\title{
GEORGE SANTAYANA: UNA FILOSOFÍA MATERIALISTA DE LA MENTE
}

\author{
GEORgE SANTAYANA: A MATERIALIST PhiLOSOPHY OF Mind
}

\section{Daniel Moreno Moreno}

Recibido: 04/05/2015

Aceptado: 14/06/2015

\section{RESUMEN}

Una filosofía de la mente à la Santayana explicaría el origen del animal humano a partir del orden de la materia. El funcionamiento social del cuerpo-cerebro que ha permitido su supervivencia lleva implícita la apertura de un ámbito nuevo - que es pero que no existe- llamado tradicionalmente: alma, conciencia o mente. Cuando ese nivel se explica desde el materialismo, se entiende tanto su origen como su especificidad no contaminada - destacando incluso el brillo del espíritu, tan atractivo para poetas y místicos-. Se evitarían así gran parte de la paradojas de la filosofía de la mente.

PALABRAS CLAVE: materia, psique, espíritu, idealismo, materialismo, filosofía de la mente, Lucrecio, Santayana

\section{ABSTRACT}

Santayana's philosophy of mind could explain the origin of the human animal from out of the order of matter. The social functioning of the body/brain nexus that has allowed it to survival implicitly carries with it the opening up of a new realm -it is but it does not exist - traditionally designated in a variety of ways: soul, conscience, mind. When this realm is explained from a materialist point of view, both its origin and its untarnished specificity are understood - highlighting even the gleam of the spirit, so attractive to poets and mystics. In this manner, a large portion of the paradoxes found in the philosophy of mind could be avoided.

KEYWORDS: matter, psyche, spirit, idealism, materialism, philosophy of mind, Lucretius, Santayana 


\section{SANTAYANA COMO LUGAR DE ENCUENTRO}

Hace ya más de veinte años que el recientemente fallecido profesor Manuel Garrido recomendaba en diversas publicaciones la lectura de la obra de George Santayana (1863-1952), a quien presentaba como "Don Quijote en Yanquilandia" (GARRIDO 1993, p. 9) o "Un Hegel con sonrisa de Gioconda" (GARRIDO 2000, p. 1). Aunque lo cierto es que la restitución de Santayana por parte de Garrido se remonta a los primeros años sesenta del pasado siglo; tal como Luis Valdés nos ha recordado no hace mucho: "algunos de sus estudiantes de los primeros sesenta han comentado estos días sus constantes referencias en clase, recién llegado a Valencia, a Unamuno, Ortega y Santayana, los filósofos españoles del siglo XX que más apreciaba" (VALDÉs, p. 205). La tesis del profesor Garrido ${ }^{1}$ es que el Olimpo del pensamiento filosófico español de la Edad de Plata está incompleto si incluye solo a Unamuno y a Ortega puesto que, en lugar de ser una pareja, en realidad es un triunvirato, que ha de incluir al heterodoxo y cosmopolita Santayana, escéptico y amante del pluralismo cultural, buen antídoto en definitiva contra la dictadura de las modas filosóficas (GARRIDO 1996, p. 9). Ha de reconocerse que en esa tarea Garrido no estaba del todo solo porque Fernando Savater, desde un ángulo acaso menos académico, también lleva haciendo constantes referencias a Santayana, a quién presentó como "pensador errante" allá por 1977, y del que ha dicho que "pertenece a la estirpe de Séneca, de Spinoza, de Kierkegaard, Nietzsche o Cioran, de los que pensaron filosóficamente para liberar sus vidas y no para dar clases de filosofía. Una raza poco frecuente en la historia del pensamiento contemporáneo" (SAVATER, p. 15).

Ha de recordarse, no obstante, que el prestigio filosófico de Santayana había declinado vertiginosamente, al acabar la Segunda Guerra Mundial, debido al ascenso del positivismo lógico. Rudof Carnap, emigrado de Europa a Estados Unidos, enseñaba primero desde Chicago y luego desde California, el modo de hacer filosofía apoyándose en el simbolismo matemático de la nueva

\footnotetext{
${ }^{1}$ La ingente labor interpretativa y editorial de Manuel Garrido ha impulsado, ya en sus últimos años, dos obras de referencia: El legado filosófico y científico del siglo XX (Cátedra, 2007) y El legado filosófico español e hispanoamericano del siglo XX (Cátedra, 2009). Pues bien, en ambas obras Santayana ocupa un lugar de relevancia, por lo que se puede decir que la tarea de Garrido en pro de la restitución de la figura de Santayana en el ámbito hispano será decisivo. En el ámbito norteamericano, ese mismo impulso, ha de atribuirse a una nómina algo más amplia: William Holzberger, Hermann Saatkamp, Angus Kerr-Lawson, John Lachs.
} 
lógica y en el fisicalismo. El impulso que le dio a esta corriente desde Harvard su discípulo más rutilante, Willard van Orman Quine, relegó a un plano casi invisible el naturalismo de influencia santayaniana y el pragmatismo deweyano. Así se explica la anécdota que Garrido recordaba en 2007: "en una ocasión en que tuve el honor de alojar a Quine en mi casa durante una de sus muchas visitas a España, me quedé atónito ante la decepción que le produjo advertir que una zona de mi biblioteca estaba repleta de libros de pensadores continentales europeos de la generación de fin de siglo, incluyendo ejemplares de las obras de Santayana. Tuve la ingrata impresión de haber bajado en pocos minutos una buena cantidad de puntos en su escala de valores" (Garrido 2007 93).

Desde los años noventa, sin embargo, se asistió, tanto en Estados Unidos como en España, a una presencia cada vez mayor de la figura de Santayana. De hecho se puede considerar que el grupo de santayanianos actuales constituye, estableciendo un puente filosófico entre ambas orillas del Atlántico, uno de los fenómenos más curiosos del panorama filosófico. ${ }^{2}$ A Santayana le encaja muy bien la metáfora de ser un puente que permite transitar a gente discreta de América y gente discreta de Europa, personas unidas por tener intereses excéntricos respecto a sus culturas de origen. Un lugar que permite no sólo cruzar de un lado al otro, sino pararse a conversar en varios idiomas y a leer lo que escriben los demás. Un lugar donde confluyen en pie de igualdad las tradiciones filosóficas continentales y anglonorteamericana y donde, por ello, se evitan tanto los habituales y persistentes prejuicios de una tradición respecto de la otra como el intento de imponer la propia, al parecer tan connatural en la reciente filosofía en inglés.

Santayana, ya un clásico de la filosofía sin adjetivos, sería así un puente filosófico entre Europa y Estados Unidos. A un lado, digamos, William James y John Dewey; al otro, Lucrecio y Spinoza. En definitiva supone el retorno de lo que durante años estuvo olvidado y reprimido, asociado incluso a un modo de leer y escribir filosofía que intenta saltar por encima de las barreras que la especialización filosófica ha levantado en un campo antaño más transitable.

${ }^{2}$ La confluencia de las tradiciones interpretativas norteamericana y europea ha dado lugar a cuatro congresos internacionales sobre Santayana. El primero en Ávila (1992), el segundo en Opole, Polonia, (2006), el tercero en Valencia (2009) y el cuarto en Roma (2012). Las actas de los tres últimos congresos están recogidas en la bibliografía.

La tranquila pero constante producción bibliográfica en torno a Santayana puede consultarse en: http://internationalconferenceonsantayana.blogspot.com.es/ 
Santayana invita a escribir para un público algo mayor que el estricto de los colegas y a abordar las grandes cuestiones filosóficas con una perspectiva de gran angular, sin enredarse en la jerga que cada autor crea para sí mismo y que, enseguida, genera la necesidad escolástica de comparar su vocabulario con el del resto de colegas, tarea que por sí sola acaba constituyendo un problema filosófico. ${ }^{3}$

En las secciones siguientes, abordaré qué puede aportar la filosofía de Santayana a la filosofía de la mente, por lo que me centraré en uno de aspectos más relevantes: la relación que establece entre materia, psique y espíritu como modo de conceptualizar la relación entre cuerpo y cerebro o entre cerebro y mente, así como la importancia que le da a ciertos estados de la mente, a los que llama "momentos espirituales". Dado que su planteamiento es materialista y que se declara repetidamente buen lector de Lucrecio, comenzaré exponiendo la antropología de este último - un autor, por cierto, más influyente, desde su recuperación en el Renacimiento, en el pensamiento moderno de lo que recoge la bibliografía de ese periodo.

\section{LUCRECIO, TAN LEJANO Y TAN CERCANO}

La relación de Santayana con Lucrecio se originó en la época de formación del primero y se mantuvo a lo largo de toda su vida. Santayana cuenta en sus memorias que el De rerum natura llegó a sus manos en una edición de bolsillo en latín sin notas, pero que "me aprendí los grandes pasajes de memoria" (SANTAYANA 2002, p. 262). En carta de 16 de enero de 1887, Santayana escribía a Henry W. Abbot: "De paso, chas leído alguna vez a Lucrecio? Si no, te aconsejaría que lo intentaras. Me produce el disfrute y entusiasmo más grandes. Los argumentos son a menudo infantiles, pero la energía, la fluidez, la magnificencia y solidez están por encima de cualquier cosa" (SANTAYANA 2001, p. 46). El padre de Santayana posiblemente dirigió también su atención hacia Lucrecio puesto que solía citar, en apoyo de sus críticas a la influencia de la Iglesia, el famoso verso "¡A tantos crímenes pudo inducir la religión!” (I 101). Se explica así el papel central que ocupa Lucrecio en la temprana obra de Santayana Tres poetas filósofos: Lucrecio, Dante, Goethe (1910), presentado como poeta de la naturaleza. En general, Santayana destaca de Lucrecio la tendencia a

\footnotetext{
${ }^{3}$ No está de más recordar que Santayana asistió al inicio de la profesionalización de la filosofía en Harvard y que seguramente ese fue uno de los motivos que le indujo a dejar su puesto de profesor en 1912.
} 
considerar a la misma naturaleza como medida de naturalidad, sin admitir criterios extra o sobrenaturales que puedan juzgarla desde fuera.

Respecto a la filosofía de la mente de Lucrecio, es sabido que queda expuesta en el libro tercero de su De la naturaleza de las cosas y que defiende la postura materialista, acaso por clásica poco visitada pero llena de interés: nos permite volver a un tiempo aún no contaminado por el subjetivismo moderno, anterior al posiblemente falso "problema de la conciencia" y cuando se podía defender que la materia — nada pasiva, nada caótica, nada rígida — siente, piensa y decide por sí sola.

Con el objetivo de vencer el miedo a la muerte, origen de la codicia, de la ambición de poder, de envidias, incluso de suicidios, Lucrecio pasa a explicar la naturaleza del ser humano, compuesto por cuerpo (corpor), alma (anima) y espíritu (animus), al que a veces llama mente (mens). El espíritu es el responsable de la sensibilidad, la percepción, la inteligencia y la voluntad. Del alma depende la vida del ser humano, se encuentra esparcida por todo el cuerpo y obedece al espíritu, alojado en el pecho, que es donde se nota el miedo y la alegría. Espíritu y alma forman una unidad indisoluble. El espíritu y el alma son partes de la persona, como la mano, no la "armonía" que defienden otros. Estos —al igual que los epifenomenalistas, diecinueve siglos más tarde- sostienen que la mente es la armonía del cuerpo, que, por tanto, no forma parte de él. Lucrecio argumenta con tres hechos que desmienten esa posibilidad - y que muestran el error de quienes piensan que el materialismo rebaja la importancia y la autonomía de la mente/espíritu-: (1) a veces, el cuerpo visible está enfermo, por lo que el espíritu tendría que estarlo también, pero el espíritu está feliz; (2) a veces, por el contrario, quien es desgraciado en su espíritu tiene el cuerpo en buen estado, igual, apunta Lucrecio, que le puede doler el pie y no la cabeza; (3) a veces, cuando el cuerpo duerme, algo en nosotros está tremendamente agitado. Es decir, a veces el espíritu goza o sufre por sí mismo, aunque nada conmueva ni al cuerpo ni al alma o a veces el temor del espíritu es tan violento que toda el alma participa de él: aparecen sudores, zumban los oídos y se desploma el cuerpo. Y a la inversa: el dardo que se clava en el cuerpo y no nos mata, sí que nos turba la mente y hace que nos desmayemos.

Hay por tanto una conexión evidente y física entre el cuerpo y la mente, lo que prueba que la mente es corporal: "este razonamiento nos muestra que la naturaleza del espíritu y del alma es corpórea; pues si ellos impulsan los miembros, arrancan el cuerpo de su sueño, alteran el rostro, rigen y manejan al hombre entero, nada de lo cual vemos que pueda cumplirse sin tacto, ni el 
tacto es posible sin cuerpo, ¿no hay que reconocer que espíritu y alma constan de naturaleza corpórea?” (III 161-167). De modo que, como el espíritu concibe y ejecuta cualquier cosa con más velocidad que cualquier cosa visible, se ha de suponer que sus átomos son esféricos y muy lisos; de hecho, argumenta Lucrecio, apenas se nota su ausencia, ni en la forma ni en el peso del cadáver comparado con el cuerpo vivo. En la vida que se escapa de los moribundos va el alma, cuya naturaleza consta de tres elementos: soplo, calor y aire, pero la sensibilidad y el movimiento de la mente precisa de otro elemento, el cuarto, que además es el más importante, a pesar de carecer de nombre: "pues esta cuarta sustancia se esconde en lo más íntimo, como fundamento de nuestro ser; nada hay en nuestro cuerpo más hondo que ella, y a su vez viene a ser el alma del alma entera. Tal como confundidas en nuestros miembros y por todo el cuerpo están latentes la fuerza del espíritu y la potencia del alma, porque son escasos y minúsculos los átomos que las constituyen, así esta innominada sustancia, hecha de elementos diminutos, está oculta y es como el alma del alma entera, y reina sobre el conjunto del cuerpo" (III 273-287).

Así que el alma, repartida por todo el cuerpo y responsable de su salud, no puede separarse sin perjuicio de ambas partes; la sensación en los órganos necesita de ambos, del cuerpo y del alma: "En fin, las facultades vitales del cuerpo y del alma gozan de vigor y de vida gracias a su estrecha unión; pues sin el cuerpo la sustancia sola del alma no puede por sí misma emitir los movimientos vitales, ni a su vez el cuerpo, privado del alma, puede subsistir ni usar los sentidos. Es decir, tal como el ojo, arrancado de sus raíces, separado del conjunto del cuerpo, no puede distinguir cosa alguna, así es manifiesto que alma y espíritu nada pueden por sí mismos" (III 558-565). De una unión tan estrecha se sigue, naturalmente, que el alma muere a la vez que el cuerpo. Tesis que Lucrecio apoya nada menos que con veintinueve argumentos, entre los que incluye la embriaguez, la epilepsia y el desarrollo conjunto y la agonía conjunta de cuerpo y alma. El alma por tanto ni existió antes de estar en el cuerpo ni puede, separada de él, mirar, oler ni recordar, ni puede transmigrar sin perder la identidad, lo que equivale a morir. De manera que, como dijo el gran Epicuro, la muerte no es nada.

Considero que no es irrelevante recordar estas ideas porque despejan el campo de la filosofía de la mente actual, un terreno donde se siguen defendiendo, supongo que eternamente, diversas formas de dualismo o claramente antinaturalistas. También Santayana pensaba que "una buena manera de calibrar cualquier filosofía es preguntarle qué piensa de la muerte" 
(SANTAYANA 1913, p. 100) y, siguiendo a su admirado Lucrecio, pensaba que la existencia de una vida futura no es cuestión de creencia religiosa, sino de investigación científica y que, en su caso, carecería de relevancia espiritual puesto que sería un proceso natural aunque prodigioso. La muerte es el fin natural de todas las cosas puesto que son esencialmente transitorias. Imaginar por tanto una vida inmortal es una ilusión sentimental basada en proyectar lo que se siente cuando algún impulso queda insatisfecho sobre la vida en su conjunto, cuando ésta, si se ha vivido intensa y armoniosamente, acaba placenteramente. Sólo hay una puerta abierta a la inmortalidad coherente con su materialismo: la inmortalidad ideal. Ésta no prolonga la vida natural ni cambia los hechos tal como ocurren, pero conserva cada imagen, cada suceso, cada persona en tanto que representaciones en la memoria y en la imaginación. Son las esencias las que son inmortales, pero estas se pueden contemplar únicamente en ciertos momentos espirituales — que serán presentados en la sección siguiente-, tan contingentes como la materia en su conjunto. Se puede afirmar, con todo, que el yo es eterno en el metafórico sentido de que la capacidad de contemplación no desaparecerá nunca en la naturaleza: "Convirtiéndose en espectador y confesor de su propia muerte y mutación universal, [quien viva en el ideal] se identificará a sí mismo con lo que es espiritual en todos los espíritus y dominante en toda aprehensión; y, concibiéndose de esta manera a sí mismo, puede sentir y creer verdaderamente que es eterno" (SANTAYANA 1954, p. 297).

Me gustaría acabar esta sección explicando por qué Santayana prefiere el término "materialismo" a "naturalismo" como calificativo para su sistema filosófico. "Naturaleza" le parece un concepto construido ya a escala humana, mientras que en el concepto "materia" cabe todo: el universo en su conjunto, cuya composición vamos lentamente desentrañando. Por eso Santayana tampoco se comprometería con el avance actual de la ciencia, es decir, no entendería como "materia" la composición que actualmente establece la física, sino que incluirá lo que haya, no exactamente lo que conozcamos. ${ }^{4} \mathrm{La}$ ciencia no tiene autoridad ontológica, es sólo un lenguaje. La antimateria, por ejemplo,

4 "Materia es propiamente un nombre para la sustancia real del mundo natural, sea la que sea. Sería por completo ocioso, e irrelevante, partir de alguna idea arbitraria de materia y argumentar que ninguna de las consecuencias que se siguen de esa idea encaja con las que la sustancia del mundo muestra con claridad. Lo que se habría probado no sería que la materia no puede tener los desarrollos que tiene, sino que esa idea concreta de materia era errónea $\mathrm{o}$, al menos, inadecuada" (SANTAYANA 1942, p. 332). 
en ese sentido, entraría bajo el concepto que Santayana tiene de "materia". También fue ese el motivo por el que le criticó a Demócrito que se comprometiera con los átomos de forma geométrica, concepción que ha resultado ser falsa. Pero tampoco le gusta hablar de "noúmeno" ni de "incognoscible" porque estos son términos, en primer lugar, negativos y, en segundo lugar, toman al ser humano como centro de referencia, cuando, siendo cierto que el ser humano es el centro de referencia para sí mismo, está muy lejos de serlo también para el cosmos, tenga este el orden que le atribuimos o tenga otro tipo de orden —acaso heterogéneo respecto a cualquier categoría humana posible.

\section{MATERIA, PSIQUE, ESPÍRITU}

La obra filosófica más importante que escribió Santayana mientras era profesor en la Universidad de Harvard fue su pentalogía The Life of Reason (1905-1906). Con su característica ironía la planteó como una respuesta naturalista al idealismo de la Fenomenología del Espíritu de Hegel, por lo que intentó reconstruir, siguiendo un orden a mitad de camino entre la lógica y la psicología, el origen de la razón, la sociedad, la religión, el arte y la ciencia a partir del caos originario. Su principio rector es todo un programa de investigación con dos principios fundamentales: (1) el origen modesto de lo que los humanos consideramos más elevado no le quita ni un ápice a su valor; más bien al contrario, cuando se intenta buscar un origen sobrenatural o irreductible a lo natural a la razón y al ideal lo que esa actitud filosófica suele esconder son intereses demasiado humanos, demasiado inferiores; (2) el origen de cualquier cosa no agota su ser: nada impide a la materia producir niveles nuevos a partir de los antiguos pero con características específicas e irreductibles a las anteriores. Los primeros capítulos del primer librito, Reason in Common Sense, donde Santayana escribe sobre el origen de la razón, de la conciencia, de los objetos naturales, de la mente y de la mente de los demás, se pueden leer todavía con provecho y creo que serían de utilidad para la filosofía de la mente. Me centraré no obstante en la obra filosofía del periodo de madurez de Santayana, donde, para el objeto de este artículo, destacan Scepticism and Animal Faith (1923), The Realm of Matter (1930 y The Realm of Spirit (1940).

\subsection{MEJOR HABLAR DE PSIQUE QUE DE ALMA, CONCIENCIA O MENTE}


Dado que a Santayana el término "alma" le parece demasiado espiritualista y cargado de connotaciones religiosas, a partir de los años veinte comienza a utilizar "psique" (psyche), como modo de aludir al componente material del ser humano. La puesta de largo fue en uno de sus deliciosos soliloquios, el titulado precisamente "La psique". Con su habitual estilo literario invita al lector a imaginar un gigante extraterrestre que observara el comportamiento del planeta Tierra. Le sería fácil observar su movimiento regular en torno al Sol y en torno a sí mismo, pero para entender el movimiento de los barcos, de las migraciones y la transformación de bosques en campo de trigo y los campos de trigo en desiertos le haría falta un tipo de imaginación parecida a la humana. Del mismo modo, un observador del animal humano podría explicar el funcionamiento de la máquina del cuerpo, pero para entender su comportamiento y su discurso mental como persona tendría que compartir con él el pensamiento. Hay por tanto para Santayana dos niveles distintos, pero ambos son materiales, en el sentido de que se deben al orden de la materia. Se separa así del idealismo empírico, para el cual la experiencia ante la conciencia existe sin más, dado que ignora su base material. Santayana compara al idealista con el joven que cree que a su padre el dinero le sale del bolsillo: igual que el joven desconoce el funcionamiento del sistema financiero, al empirista se le oculta la vida del cuerpo, el orden natural que explica el surgimiento, la interrupción y la renovación de la experiencia. Por ello, Santayana llama psique al fundamento de los dos niveles antes mencionados:

Con la escala humana de observación, los hábitos observados con mayor facilidad son los hábitos mayores de los seres vivos; así que al principio de esos hábitos, transmitido por una semilla, lo llamo la Psique: es o un complejo de los hábitos más diminutos de la materia o un ritmo dominante impuesto sobre ellos por el hábito de la especie. Muchos filósofos griegos enseñaban que la Psique era material; incluso Platón, aunque su Psique podía por supuesto llegar eventualmente a pensar, la consideraba ante todo un principio de movimiento, de crecimiento y de gobierno inconsciente; de modo que las asociaciones de la palabra Psique no son tan repugnantes, como sí lo son las de la palabra alma, para el significado que yo deseo darle: ese hábito de la materia que forma el cuerpo humano y la mente humana (SANTAYANA 2009, p. 214). ${ }^{5}$

\footnotetext{
${ }^{5}$ Creo que Santayana hubiera celebrado el descubrimiento del código genético de todos los seres vivos: una regularidad físico-química que se transmite de generación en generación, donde van encriptadas las pautas que guiarán el desarrollo biológico y, en su caso, psíquico
} 
Para evitar malentendidos, Santayana aclara que, en el caso humano, la psique no es la conciencia, sino los procesos materiales relacionados con los fenómenos morales y mentales: "el cuerpo de un hombre es una suerte de cáscara de la cual la Psique (ella misma material) es la almendra; y es a partir de las predisposiciones de esa semilla viva, con la que las circunstancias juegan constantemente, como se forma el carácter y la mente del hombre" (SANTAYANA 2009, p. 215). La psique por ello se ve obligada a morir o a sobrevivir: "La Psique, al ser esencialmente una forma de vida, una suerte de código animado de higiene y de moral, es un principio muy selectivo: está distinguiendo perpetuamente - en la acción, si no en palabras- entre bueno y malo, correcto y erróneo" (Ibid.).

Armado con el concepto "psique", Santayana puede abordar la complejidad del ser humano y no quedar atrapado en su descripción idealista. Así, cuando en Escepticismo y animal analiza las sublimaciones de la fe animal y se encuentra con el tradicional término "alma", puede proceder a deconstruirlo en tres niveles o planos del ser distintos. Por un lado, la psique, en tanto que mecanismo de la materia heredado que forma y utiliza los órganos externos del cuerpo, "pero - matiza Santayana- no es más que la sutil y vivaz organización interna del animal material, no una cosa diferente de él" (SANTAYANA 2011, p. 256). Este nivel es el que los salvajes o los niños creen que, a modo de cuerpo tenue y similar en aspecto y poderes a la persona, abandona el cuerpo en la muerte o en el sueño. Por ello, argumenta el siempre irónico Santayana, en un mundo de fantasmas, se seguiría pensando que cada fantasma se comporta tal como lo hace debido a su alma interior. El segundo nivel precisa de un observador ante el que ese hábito de la materia se presente en su unidad y ritmo, no en su funcionamiento oculto, sino como comportamiento, como propósitos, tendencias y esfuerzos, hostiles o amistosos, en definitiva, una voluntad. Aparece así una unidad del discurso, no un objeto nuevo ni un poder: "y a esa unidad del discurso, que cuando es real pertenece al reino de la verdad, la toma supersticiosamente por una sustancia o un poder. Imagina que él mismo es una voluntad y un poder que reacciona a otras voluntades y poderes; como si esos hábitos o relaciones pudieran ser previos a los términos que los componen o pudieran crear esos términos" (Id., p. 257). Este nivel es subjetivo y moral, pero la tendencia humana a dotar de

futuros. Más aún se hubiera alegrado al saber que ese código no es determinista al modo newtoniano, sino que incluye zonas dúctiles, que explican la flexibilidad ante el cambio. 
sustancia a las unidades del discurso ha dado lugar a la creencia en los dioses y en los demonios como poderes metafísicos, "sin embargo, la magia de imágenes y palabras es indirecta: estarían vacías si sutiles influencias materiales no fluyeran por ellas y se escondieran tras ellas, tornándolas emocionantes para el alma material del observador" (Id., pp. 257-258). El tercer nivel es "una corriente de intuiciones que expresa las modificaciones que [la vida animal] sufre ante la presencia de otros cuerpos o ante las agitaciones de su propia sangre" (Id., p. 258). Es a lo que la psicología llama sensaciones, ideas y emociones y que Santayana llama "modos del espíritu [que] son intangibles, inobservables, volátiles y fugitivos; y si cabe llamar insustancial a algo que es real, sobre lo que puede plantearse la verdad y el error, entonces nada puede ser más insustancial” (Ibid.). Sólo metafóricamente se puede decir, por tanto, que las sensaciones ocupan un lugar y un tiempo, y sólo la imaginación dramática puede adivinar las emociones de otra persona, nunca la comprobación empírica directa. La mente "sería una sustancia si el idealismo fuera cierto; pero en realidad es una traducción a términos morales, rápida, sumaria y profética, de una vida animal que transcurre muy laboriosa y persistentemente en la sombra; y esa vida animal no es ella misma una sustancia especial, sino un modo especial o vórtice en la sustancia general de la naturaleza" (Id., p. 259).

La particularidad del término "psique", por tanto, lo que lo distingue de las demás alternativas, es la renuncia a considerar por separado aspectos que en la vida se dan juntos, digamos, el cuerpo y el alma, o el cerebro y la conciencia, o el cerebro y la mente. Santayana considera que si la medicina o la psicología los separan por comodidad han de tener muy en cuenta esa decisión para no quedar atrapados en paradojas, pero que lo que se da en el planeta Tierra son seres humanos vivos y "completos". Por eso, cuando, a partir de 1927 da a conocer el ambicioso proyecto ontológico ${ }^{6}$ de distinguir entre esencia, materia,

\footnotetext{
6 Santayana dio a conocer el fundamento completo de su sistema ontológico en "Some Meanings of the Word "Is"' [Journal of Philosophy 1924]. Ahí distinguió hasta siete sentidos de la palabra "es", el sexto de los cuales estaba reservado precisamente para el espíritu: "Esta hipóstasis espiritual de la vida en la intuición es por tanto menos y más que la existencia natural y merece un nombre diferente. La llamaré actualidad [actuality]. Es, aplicado al espíritu o a alguno de sus modos, significa por tanto es actual; en otras palabras, existe no en virtud de la inclusión en el dinámico, incesante e infinitamente divisible flujo de la naturaleza, sino por su intrínseca incandescencia, que trae a la luz las esencias y crea el mundo de las apariencias" (SANTAYANA 2006a, p. 24); "Aunque en esta existencia superlativa propia de la intuición hay
} 
verdad y espíritu, no ha de extrañar que de la psique se ocupe en El reino de la materia.

El objetivo último de Reinos del ser fue aclarar las confusiones categoriales que Santayana detectaba en los planteamientos del neorrealismo y del pragmatismo norteamericanos, entendidos como dos formas de idealismo. De ahí que esté muy prevenido contra la reificación de las palabras y aclare que sus conceptos filosóficos, como todas las palabras, no definen su objeto, sino que sólo lo señalan. En el ámbito de la esencia incluyó el conjunto de esencias, en tanto que idénticas, simples y de tipos muy diferentes - un color, un significado, un círculo, el ser-; el reino es infinito, eterno, ahumano y no ocupa lugar, es decir, propiamente, no existe. En el ámbito de la materia incluyó el conjunto de hechos existentes y sucesos que ocurren - el universo, la naturaleza, las personas, el libro que se lee, el sonido con que se habla-, junto con su influencia en la psique de los seres vivos; el reino es contingente, infinito, y también ahumano. El ámbito de la verdad incluye el conjunto de esencias que describan fielmente lo ya ocurrido en el reino de la materia, sería la visión comprensiva y justa de todas las cosas, hasta sus mínimos detalles, atribuida tradicionalmente a Dios; este reino es invariable - lo ocurrido ocurrido queda-, ahumano y contingente, puesto que recoge lo que sucede en el ámbito de la materia. Finalmente el ámbito del espíritu es la dimensión abierta por la psique cuando deja de estar inmersa en el mundo, se detiene acaso y alcanza la intuición de esencias, en especial el conjunto de esencias que alimenten y entusiasmen al espíritu.

La distinción entre el reino de la esencia y el reino de la materia va dirigida contra el neorrealismo y su confusión del objeto estético o lógico de la experiencia subjetiva o del lenguaje -lo dado, sensibilia, fenómenos, significados - con el mundo material, donde habitan los animales que nos matan o que nos ayudan, pero no los círculos ni las experiencias. Frente a los pragmatistas, Santayana distingue entre el reino de la verdad, esto es, la verdad de verdad, que, aunque seguramente sea inaccesible al ser humano, no ha de confundirse con lo que conviene en cada momento. También a ellos va dirigido el reino del espíritu, donde se incluye todo lo que no sirve

algo irónico. Mientras que existe tan positivamente que ciertos filósofos no admiten otra realidad, no se puede descubrir en el contexto natural donde la existencia debe estar" (Id., p. 23). 
directamente para sobrevivir ni para ganar dinero: ocio, fruición, creación ${ }^{7}$. Para Santayana sólo existe la materia, pero hay más cosas: esencias. Como las esencias no existen, ni se pueden reducir a existencias ni eliminar; lo que consigue la ciencia es encontrar explicaciones físicas a sucesos que parecían inexplicables, pero así ni reduce ni elimina nada físico, en todo caso, si la explicación es correcta, avanza el conocimiento. De modo que si el fisicalismo pretende reducir, literalmente, lo psíquico a lo físico, o establecer su identidad - algo muy distinto es que no pueda explicarlo y prefiera cambiar de tema-, Santayana lo vería ridículo: el contenido de lo psíquico pertenece al ámbito de la esencia, si bien la actividad de la psique pertenece al ámbito de la materia; es decir, el color de una flor visto por una persona no es algo físico, pero la actividad natural necesaria para percibir ese color sí lo es. Pero también rechazaría de plano el dualismo en sentido fuerte porque lo psíquico no es sustancial en ningún sentido del término, lo psíquico es, pero no es sustancia. Cuando el dualista sustancializa la mente parece que la trata con más respeto, pero es al revés, ocurre como con la divinidad: quienes dicen que creen en ella, la suelen comprometer en sus batallas, mientras que los que la niegan al menos la dejan tranquila. Respecto al emergentismo, Santayana lo conoce y lo acepta, pero entiende que lo que emerge es un nivel físico más complejo de otro nivel inferior, nunca lo psíquico de lo físico, puesto que son dos niveles del ser no interconectados.

Volviendo a El reino de la materia, cuando Santayana expone su concepción de la psique como hábito de la materia, tanto vegetal como animal, que se transmite como semilla y se desarrolla biológicamente, es consciente de ir contra el uso habitual de los términos: "la psicología literaria entiende habitualmente lo psíquico simplemente como lo mental, de modo que el lector

\footnotetext{
7 Cuando la distinción santayaniana se pasa por alto, se puede caer en la siguiente confusión de niveles: "Lo que llamamos "mente" no es sino el límite de lo material, esto es, aquel estado en cuyo seno "lo funcional" se emancipa progresivamente de lo estructural, como se comprueba en el caso de las formas puras que nos descubren las matemáticas: un triángulo representa un límite ideal, pues no existe materialmente. Lo mental, en el caso del ser humano, jamás emerge como "mente pura", sino como materia revestida de una gran complejidad y funcionalidad. Con el origen de la conciencia parece haberse rasgado, aun tímidamente, un "velo de Maya" en la trama evolutiva, gesta que nos permite contemplar un universo de permanencia: el de las formas, el de los conceptos, el de las ideas; el del pensamiento, al fin y al cabo, cuya autonomía desborda la rigidez (incluso si admitimos también su exquisita complejidad) de la materia" (BLANCO, p. 259).
} 
se encontrará desconcertado ante la sugerencia de que lo realmente psíquico, la vida dinámica del cuerpo y de la mente juntos, es, por el contrario, material" (SANTAYANA 1942, p. 331). Pero Santayana insiste es que esa es precisamente su intención: "supone el deliberado rechazo a admitir la posibilidad de cualquier maquinaria mental. La maquinaria del crecimiento, del instinto y de la acción, igual que la maquinaria del habla, es por completo física: se llama psíquica a ese tipo de acción física porque ocurre dentro de un tropo ${ }^{8}$ (trope) vital y forma parte de la autodefensa y autoexpresión de un organismo vivo" (SANTAYANA 1942, p. 332). La psique es así un campo de investigación, abierto para la biología, la psicología conductista o el psicoanálisis. Pero Santayana no fue experto en esos campos, intrincados y misteriosos, su objetivo era más sencillo, acaso más ambicioso: una vez presentada la psique, a él le interesa el espíritu.

\subsection{DE LA PSIQUE AL ESPÍRITU O DE LA VIDA ORDINARIA A MOMENTOS QUE POR EXTRAORDINARIOS NO PARECEN VIDA}

Sucintamente presentada la distinción entre psique y espíritu, psique correspondería a la vida ordinaria y espíritu a ciertos momentos especiales de la vida. Es una distinción que seguramente se da sólo en los animales humanos. La psique humana permite sentir, hablar y pensar, de modo que es capaz de esparcir su semilla por todo el planeta. Su objetivo es sobrevivir y vive inmersa en trabajos constantes. Pero a veces la psique - por agotamiento, por exceso de energía o simplemente porque sí- se detiene, vuelve sobre sí, contempla, piensa sabiendo que piensa, se pregunta qué hacer o disfruta sintiendo que siente. A estos momentos les dedica Santayana una atención especial. Tanto es así que siempre que habla de la psique, lo hace en contraposición con el espíritu. Ya en citado soliloquio "La psique" utiliza una bella metáfora: la psique es una madre ciega que da milagrosamente a luz un hijo, no sabe de qué padre, al que es incapaz de entender: su hijo sólo ríe, medita, juega, reza, poetiza, es inútil, pero

él ve, lo cual es un misterio para ella porque, aunque ella siempre ha actuado como si, de algún modo, notara las cosas a distancia, nunca ha visto ni ha podido ver nada. Tampoco le son a ella de ninguna utilidad los sentidos de él, a pesar de toda su vivacidad. Porque ¿qué le muestran a él? Siempre algo

\footnotetext{
8 "Tropo" es un término técnico en Santayana que nombra todo tipo de regularidad observada en el movimiento de la materia. En el caso de la psique, es un ordenamiento material capaz de sentir y pensar. Si nos situamos en la conciencia, digamos pura, los movimientos y armonías de la psique serían su "órgano y soporte inmediato" (SANTAYANA 1942, p. 332).
} 
irrelevante: un haz de luz polvoriento a través de las vigas, una llama azul bailando en las ascuas, un murmullo, un borboteo de agua, un aliento de calidez o de frialdad, un hastío mortal o una infundada alegría - todo imágenes oníricas, visiones de un mundo divertido, esencias pintadas en el aire, tales como podría inventar cualquier poeta ocioso-. Pero el hijo se preocupa por ellas enormemente: rebosa lágrimas repentinas y celosos pequeños amores (SANTAYANA 2009, p. 216). ${ }^{9}$

Tan radical es la novedad que aporta el espíritu que tradicionalmente se ha buscado un origen más elevado a las funciones espirituales. La simple diferencia de un momento a otro de la psique se convierte así en la separación ontológica entre cuerpo y alma, entre tierra y cielo. Según Santayana, sin embargo, todo lo atribuido al alma y al cielo procede, obviamente, de la tierra, sin perder por ello ni un ápice de su carácter divino, más bien, apareciendo en toda su especificidad. El desconcierto ante las funciones espirituales de la psique no se elimina construyendo un cosmos ad hoc, sino aceptando el hecho como algo milagroso, pero natural. Si se imagina al espíritu desencarnado, hay que imaginarlo forzosamente sin relevancia moral para la existencia, perdería toda la sabiduría potencial, sería un intelecto abstracto, pero sin vida espiritual. Ciertamente, la psique, a veces, mira el mundo no sólo bajo el esquema agradable-desagradable, amigo-enemigo, sino desinteresadamente, por simple curiosidad. El espíritu no tiene vida por sí mismo al no ser sustancial, la vida se la debe a la psique. Por eso el espíritu no puede ser nunca puro, ni eterno, ni inmortal. Estas características se pueden atribuir a las esencias, pero no al momento en que las esencias son intuidas. Son momentos espirituales, momentos de la psique con lugar y tiempo determinados. Sólo hay momentos de la psique, que pueden, en algún caso, ser vividos simultáneamente de dos formas, pero el momento espiritual no es ontológicamente diferente del momento vivido sólo desde la psique. Independientemente de las resistencias

\footnotetext{
9 "Pero el espíritu es un inquilino del alma animal terriblemente traidor, se ha colado dentro, como afirma Aristóteles, desde fuera de las puertas: y su casa es el desierto. Esta extranjería es moral, no genealógica: el espíritu se nutre de la psique porque la psique, al vivir, está obligada a adaptarse a cosas distintas: lo hace así en su propio interés, pero al tomar conocimiento de otras cosas, al moldear una parte de sus sueños para seguir las distintas vicisitudes de las cosas, se hace inteligente, crea el espíritu; y este espíritu sobrevuela la función pragmática de la sensibilidad física -es el acto mismo de sobrevolarla-, mostrando así que es un extranjero de categoría, un hijo rebelde a su casa familiar, un Ismael que vaga solo, un habitante del infinito" (SANTAYANA 2006b, p. 50).
} 
de los diversos críticos a esta doctrina, el principio es obvio para Santayana y, de hecho, todos los ejemplos que se encuentran en sus obras recogen el aspecto pasajero de la vida espiritual, por más que, mientras dura, pueda parecer una vida eterna.

La descripción pura, es decir, menos literaria, de estos momentos espirituales se encuentra en Escepticismo y fe animal. Son momentos en que queda suspendido el juicio animal, que es el que convierte cualquier imagen dada en manifestación de una sustancia o de una idea en la mente o de un evento en el mundo. En el momento espiritual, si la imagen es un color es visto como tal color, si es música como tal música y si es un rostro como tal rostro. Todo el campo de la intuición es ocupado por una esencia. En ésta, por tanto, todo es superficie, no hay tercera dimensión, no se puede dirigir hacia otro referente más allá de ella misma. Cada esencia es captada en una aprehensión instantánea. El espíritu se entretiene en la inmediatez estética y en la definición lógica de la esencia. A tan alto precio se consiguen momentos de seguridad total porque no hay posibilidad de error, y de eternidad porque no hay ni antes ni después. A un lado quedan las confusiones de las opiniones humanas y la incapacidad de cumplir los objetivos del dogmatismo. La mente queda libre de ansiedad, iluminada en una soledad dulce y maravillosa. La renuncia obtiene su recompensa: un paraíso de paz y variedad sin fin (SANTAYANA 2011, pp. 9699).

Vivir desde estos momentos, meditando sobre lo que suponen y sobre el punto de vista que se alcanza, puede transformar al ser humano, acaba por hacer su vida diferente de la del resto de personas. Se descubre y se disfruta una nueva dimensión: el pensamiento en sí mismo, que aporta un tipo de paz y tranquilidad desconocido por la existencia. En el espíritu no hay urgencia, no hay problemas morales ni personales, hay ganancia plena respecto a la vida común, el espíritu se reconcilia consigo mismo sin pretender imponerse al mundo, se siente salvado.

$\mathrm{Y}$ es curiosamente un autor materialista quien aísla el campo del espíritu con tal mimo que evita la habitual materialización que de él llevan a cabo los pensadores idealistas o espiritualistas. Para ello da a conocer, en El reino del espiritu, un pequeño glosario donde distingue entre: cuerpo, organismo, psique, animal, alma, yo o persona y, finalmente, espíritu, presentado así:

Otros nombres para espíritu son conciencia, atención, sentimiento, pensamiento o cualquier palabra que señale la completa diferencia interna entre 
estar despierto o dormido, vivo o muerto. Esta diferencia es absoluta moralmente, pero, físicamente, el nacimiento del espíritu corona el largo crecimiento en el que potencialidades y excitabilidades variadas se concentran en los organismos y se transmiten. La diferencia externa entre dormir y estar despierto, vivo o muerto, no es absoluta, de modo que se pueden seguir las diferencias entre el camino por el que la psique se transmite y el fundamento de la distribución del espíritu [...] En el espíritu, por definición, nada hay persistente o potencial. Es luz pura y actualidad [actuality] perpetua. (SANTAYANA 1942, p. 572).

Y a la intuición le dedica el capítulo sexto, donde —en compañía de santos, poetas y místicos - despliega toda una fenomenología del espíritu, alejándose ostensiblemente de los temas habituales de la filosofía de la mente. De modo que dejaré aquí el recorrido por Santayana y acabaré con dos apuntes personales surgidos al hilo de la preparación del presente artículo.

\section{DE TRADUCTORES Y DE RASCACIELOS}

La primera reflexión es que el lenguaje, como siempre, nos traiciona, también en el ámbito de la filosofía de la mente. "Cerebro" es una palabra que se refiere a un objeto, "mente" es también una palabra, pero ¿a qué refiere? Nunca a nada del tipo de cosas al que pertenece el objeto referido con "cerebro", luego entre los referentes de ambas palabras no hay relación, porque no están al mismo nivel. Si se acepta esta interpretación, desaparece el problema sobre la relación mente-cerebro. Ahora sabemos que, cuando el cerebro humano está integrado en un cuerpo y este mantiene relaciones con otros cuerpos -incluyendo, claro, adminículos ópticos y auditivos, implantes cocleares, elementos ortopédicos y aplicaciones informáticas que conecten a sujetos con capacidades disminuidas con su mundo entorno físico y social—, el cerebro hace sentir, recordar, imaginar, soñar, pensar, hablar, escribir, leer, escuchar, crear, creer y ser alguien - normalmente muchos alguien, que se suceden, se alternan, se ayudan y se recriminan-; también sabemos que, cuando los humanos tenemos una palabra, creemos tener una cosa; es decir, es habitual adjudicar un objeto como referente a las palabras que utilizamos: llamo mesa al objeto en que me apoyo para escribir, hasta aquí no hay problema, pero ¿y si busco el objeto a que se refiere la palabra "mesa" en general? En ese caso, no busco mi mesa habitual ni ninguna otra existente o por construir. Las soluciones históricas a este problema han sido hablar de un 
mundo especial donde habitan esos objetos universales o considerar que no hay tales objetos en ninguna dimensión, por lo que la palabra simplemente etiqueta al conjunto de objetos particulares parecidos a mi mesa habitual.

Las paradojas surgen con la palabra "mente". El objeto al que cada cual la refiere suele ser la mente propia, lo que se conoce como perspectiva de primera persona, exactamente se utiliza para nombrar el largo conjunto de actividades enumerado más arriba; como esas habilidades nadie las ha aprendido estando solo sino siempre en grupo, cada cual acepta que igual que él siente, sienten los demás, de ahí que cuando uno habla otro responde, o calla cuando otro calla, o uno le ayuda a recordar a otro, o consigue emocionarlo o enfadarlo o hacerle entender algo o sumirlo en dudas de todo tipo; es decir, cada cual da por supuesto, antes siquiera de hacerse tal pregunta, que eso que él llama mente también lo tienen los demás. El problema sigue siendo la expresión "tener mente", porque la mente no se tiene, no es un objeto, el cerebro sí lo es, mi mesa también, la mente no. La relación entre mente-cerebro no es por tanto como la relación mesa-silla; de hecho, no es una relación. Ahí está el problema.

La primera sorpresa es que tampoco sería cierto decir que "no tenemos mente". Ya William James se preguntó si existía la conciencia y respondió que, si se entiende existir en sentido fuerte, la conciencia no existe. Pero, puesto que no existe, no se la puede eliminar. Cuando se defiende cualquier tipo de reduccionismo, se quiere decir que la palabra "mente" genera más problemas que soluciona, pero en nada afecta al hecho de que cada cual sienta, lea o imagine; es más, quien escribe sobre los peligros de la palabra "mente" está llevando a cabo una de las actividades a la que esa palabra refiere. Úsese pues "mente", pero sabiendo que no refiere a objetos y que, por tanto, no genera ningún problema mente-cerebro. Habría que decir que son dos lenguajes distintos: o se habla en el lenguaje que utiliza palabras como cerebro, neuronas, sinapsis y neurotransmisores, o en el lenguaje que habla de mente, sentimientos, percepciones, voluntad, persona, yo, creencias, pensamientos. El lenguaje que utiliza "cerebro" habla de niveles de integración en el cerebro, de la relación bidireccional del cerebro con el cuerpo y de este conjunto - al que hay que añadir todos los instrumentos que utiliza habitualmente- con el entorno. El lenguaje que incluya "mente" recogerá la fenomenología de la actividad mental, su aspecto cualitativo, hablará de personas, libertad y responsabilidad. Pero la mente no es un órgano - esto lo es el cerebro- ni entra en contacto con nada - esto lo hace la mano, la piel o los instrumentos. 
Sólo metafóricamente se puede calificar a la mente como encarnada, incorporada o embebida (cf. PÉREZ ChICO 2010). Pero no son buenas metáforas puesto que recuerdan la relación tradicional alma-cuerpo; el alma, entendida tradicionalmente como sustancia, sí que se encarna al unirse al cuerpo, pero no creo que esa sea la ontología que defiende la teoría de la mente encarnada. Por otro lado, habría que preguntarse dónde y cuándo se da un cuerpo humano vivo sin mente; de modo que, si lo que se quiere decir es que la mente siempre va con el cuerpo, también valdría hablar de cuerpo mentalizado, que vendría a ser al cabo una traducción, en dos palabras, de la psique santayaniana. En esta misma línea, me parece que la exitosa metáfora de Putnam que compara al cerebro con el hardware y la mente con el software se puede reciclar pero considerando que es la psique completa la que funciona como hardware y la educación y la experiencia vivida serían el software.

Finalmente, creo que, en un sentido, se puede decir que la mente lo es todo, nunca un mero algo (cf. PINEDo 2014), en tanto que, sin cerebro no seríamos personas autoconscientes; por otro lado, en tanto que conciencia, se puede decir que la mente, literalmente, en sentido fuerte, no es nada. La actividad electroquímica responsable de lo mental pertenece al cerebro.

Este planteamiento permite eliminar, creo, la susceptibilidad frente a los reduccionismos y a los eliminacionismos. Estos se plantean siempre dentro del lenguaje y pretenden sustituir un concepto por otro, bien por motivos de control científico bien por presupuestos filosóficos, pero no afectan nunca a lo reducido ni a lo negado, que, sea lo que sea, se mantiene incólume. En su momento también se les llamaba desalmados a los negadores del alma y no hace tanto que algunos estructuralistas tenían que explicar que su antihumanismo teórico nada tenía que ver su supuesta ceguera ante las matanzas más allá del telón de acero. Es un síntoma, en el fondo, asociado a la tendencia, ¡tan humana!, de reificar las palabras: parece que si eliminamos el concepto "mente" estamos eliminando también nuestra vida mental. No está de más recordar, con René Magritte, que una cosa son las palabras y otra cosa son las cosas. Pase que Jahvé, como Palabra, creara el mundo hablando, pero que también creamos que un filósofo puede borrar la realidad borrando la palabra es muy otro asunto. 
Lo más necesario sería entonces contar con buenos traductores ${ }^{10}$. Pero es también conocido el placer que los humanos obtienen con discusiones bizantinas sobre el sentido y uso de las palabras, y que gran parte de ellas, las más endiabladas, surgen precisamente cuando se quieren evitar las polémicas. Hay placer en esa condena. Pero no luz.

Santayana, por su parte, estaría muy atento, no tanto a las discusiones de la filosofía de la mente, cuanto a los rápidos avances actuales en el conocimiento sobre el funcionamiento del cerebro en el ser humano (cf. LERMA 2015) y en el resto de animales gregarios, así como en el desarrollo de la inteligencia artificial. De hecho, durante su vida, estuvo muy atento siempre a las novedades científicas, como muestran sus referencias a Einstein, a la nueva física o al psicoanálisis. Llegó a escribir incluso un artículo sobre las revoluciones científicas, donde, en lugar de defender a la filosofía del supuesto predominio de la ciencia, detectó, en la vorágine creada, la presencia de los eternos enemigos de la ciencia, que no son sólo los supersticiosos y los adivinos, sino también cierta metafísica romántica empeñada, como siempre, en negar la materia y en resucitar el libre albedrío en el corazón de la naturaleza - también ahora Roger Penrose cree encontrar en la no computabilidad del nivel cuántico la base para la no computabilidad de la conciencia humana-. Santayana, irónico, les señala a los idealistas que la negación de la materia se hace desde la materia y a los ilusionados científicos les dibuja un horizonte cargado de interrogantes (Cf. SANTAYANA 2005).

Santayana esperaría que, esta vez, los filósofos no se queden atrás, que ayuden a desenredar los lazos que surjan por la influencia de los presupuestos filosóficos, siempre adheridos a cualquier teoría científica, y a evitar que aparezcan confusiones nuevas. También les pediría que sean los portavoces de las cuestiones eternas, esas que a él le preocupaban especialmente: ¿qué nivel

\footnotetext{
10 Sirvan varios ejemplos: la frase "una de las cosas del mundo soy yo" confunde los dos lenguajes, dado que habría que distinguir entre el ámbito donde hay yoes y el ámbito donde hay cosas, de lo contrario o bien se cosifica al yo o se psicologizan las cosas; en la frase "la mente es un aspecto básico de la naturaleza" se corre el peligro de identificar mente con naturaleza, cuando gran parte de la naturaleza no presenta aspecto mental; la frase "el lugar que la mente ocupa en el mundo" atribuye a la mente un lugar en el mundo, cuando lo que hay en el mundo son cerebros en humanos, en realidad, la mente abre una perspectiva, un ámbito específico, pero no ocupa un lugar; en las expresiones "causalidad mental" y "causalidad neurofisiológica", se utiliza la palabra "causa" en dos sentidos distintos, si no se advierte ese matiz, puede parecer que habría dos causas, cuando no se pueden sumar: son, de nuevo, dos niveles distintos.
} 
del cerebro o que conjunto de interacciones en su interior son responsables de los momentos espirituales?, ¿qué efectos produce su ejercicio en el resto del cerebro y, por ende, en la imagen general que ese individuo tiene de sí mismo, de su puesto en el cosmos?, ¿cómo se ve afectado también el comportamiento de esa persona?, ¿habría diferencias individuales en ese terreno?, ¿son zonas o interconexiones modernas o antiguas, en términos evolutivos? ${ }^{11}$ Por una vez se podría evitar la recurrente pregunta por el interés adaptativo de los momentos espirituales —acaso no sean más que otra ociosidad en un conjunto de inutilidades sin fin.

Mi segunda reflexión enlaza con la anterior y con el gusto por las metáforas para explicar el funcionamiento del cerebro. Propongo imaginarlo como un conjunto de rascacielos con un número de plantas de diversa extensión y altura - a determinar por las ciencias cognitivas-, comunicadas entre sí a diversos niveles y con ascensores que conecten las distintas plantas - seguramente no todos los ascensores van de la planta primera a la última, es más, es de esperar que ninguno lo haga sino que arranquen, paren y lleguen a plantas distintas; por ejemplo, de la uno a la diez, de la tercera a la séptima, de la octava a la quinceava, etc. El material de los rascacielos sería naturalmente flexible, de modo que su estructura explique pero no determine unívocamente su función.

Se ha avanzado rápidamente en la localización de las zonas responsables de las actividades del cuerpo y de gran parte de las actividades de la llamada mente: percepción, lenguaje, sentimientos. Quizá nos falta localizar o aislar el rascacielos, o las plantas de algunos de ellos comunicadas entre sí responsables de los distintos niveles de conciencia. En varios de ellos ocurrirán los fenómenos que ocupan a las corrientes psicoanalíticas porque, sin duda, se refieren a sucesos que pasan en el cerebro, ¿dónde si no? Pero los niveles que más me interesan son las plantas de los rascacielos responsables de los siguientes hechos: donde se resuelven problemas matemáticos durante el sueño, las que producen las improvisaciones de un músico de jazz o de flamenco, las que inspiran a los poetas sus poemas de un modo que ellos mismos suelen describir como "dictados por las musas", las que ponen las

11 A estas cuestiones se podrían añadir algunas más, como por ejemplo: ¿cómo afecta el cambio de teoría de la mente a la autoconcepción de cada cual?, ¿dónde y cómo actúa la sesión del psicoanalista, la conversación con el amigo o la absolución del confesor?, ¿qué cambia en la autoconcepción de alguien cuando deja de autoentenderse desde el horóscopo occidental y se pasa al horóscopo chino? 
palabras justas en el lugar adecuado durante un largo discurso no escrito, la que se encarga de dirigir la Séptima Sinfonía de Shostakovich, las que toman las decisiones y las pasan a la planta superior donde se cree que el curso de la acción o del pensamiento se ha elegido libremente, es decir, donde aparece la metarrepresentación de la persona como agente autónomo y soberano y donde, curiosamente, se acepta por ello la responsabilidad por las consecuencias de esa acción, aceptando como propio lo que viene de la planta de abajo; en fin, me interesan también vivamente las últimas plantas, donde se toca el cielo.

Daniel Moreno

I.E.S. Miguel Servet

dmoreno@unizar.es

\section{BIBLIOGRAFÍA}

BELTRÁN, J. (2005): "La ontología de Santayana", en El legado filosófico y científico del siglo XX, M. Garrido, Luis M. Valdés y L. Arenas, eds., Madrid: Cátedra, pp. 156163.

BeltrÁn, J. (2008):2 Celebrar el mundo. Introducción al pensar nómada de George Santayana, Valencia: Universitat de València.

BLANCO, C. (2014): Historia de la neurociencia. El conocimiento del cerebro y la mente desde una perspectiva interdisciplinaria, Madrid: Biblioteca Nueva.

GARRIDO, M. (1993): "Don Quijote en Yanquilandia" [Introducción a George Santayana, Interpretaciones de poesía y religión, traducción de Carmen García Trevijano y Susana Nuccetelli], Madrid: Cátedra, pp. 9-31.

GARrido, M. (1996): "Prólogo desde el mundo" [Introducción a Jorge Santayana, Diálogos en el limbo, traducción de Carmen García Trevijano], Madrid: Tecnos, pp. 9-14.

GARRIDO, M. (2000): "Un Hegel con sonrisa de Gioconda”, Limbo (Teorema XIX/3) $\mathrm{n}^{\mathrm{o}} 12$, (2000), pp. $1-2$.

http://dialnet.unirioja.es/servlet/articulo?codigo $=4396155$.

GARRIDO, M. (2007): "Cómo construirse una cabaña entre las ruinas de la creencia religiosa", Limbo. Boletin internacional de estudios sobre Santayana, $\mathrm{n}^{\circ}$ 27, (2007), pp. 91-105. http://dialnet.unirioja.es/servlet/articulo?codigo $=2745563$

KerR-Lawson, A. (2005): "The Autonomy of Spirit", Overheard in Seville. Bulletin of the Santayana Society, $\mathrm{n}^{\circ} 23$ (2005), pp. 33-37. http://indiamond6.ulib.iupui.edu/cdm/compoundobject/collection/Santaya $\mathrm{na} / \mathrm{id} / 1798 / \mathrm{rec} / 23$. 
Kerr-Lawson, A. (2006): "On the Supervenience of Spirit", Overheard in Seville. Bulletin of the Santayana Society, no 24 (2006), pp. 28-34. http://indiamond6.ulib.iupui.edu/cdm/compoundobject/collection/Santaya $\mathrm{na} / \mathrm{id} / 1752 / \mathrm{rec} / 24$.

LERMA, J. et alii, (2015): "El cerebro. Ese gran reto", SEBBM [Sociedad Española de Bioquímica y Biología Molecular], nº 183, (2015): 4-26. http://www.sebbm.com/revista/imagenes/revistasebbm_0183.pdf.

LuCRECIO, T.C. (1986): De rerum natura / De la naturaleza de las cosas, edición bilingüe de Valentín Fiol, Barcelona: Bosch.

Moreno, D. (2006): "El testamento espiritual de George Santayana", Estudios Filosóficos, 55/158 (2006), pp. 83-106.

Moreno, D. (2007): Santayana filósofo. La filosofía como forma de vida, Madrid: Trotta.

PÉrEZ CHICO, D. (2010): "Los límites de la tesis de la mente extendida: agencia, autonomía y autoridad epistémica", Factótum, no 7, (2010), pp. 62-75. http://www.revistafactotum.com/revista/f_7/articulos/Factotum_7_6_Davi d_Perez.pdf.

PÉREZ CHICO, D. (2014): "Entre la materia y el espíritu. Santayana 150 años después de su nacimiento", Limbo. Boletín internacional de estudios sobre Santayana, $\mathrm{n}^{\circ} 34$ (2014), pp. 101-114. http:/ / dialnet.unirioja.es/servlet/articulo?codigo $=4855403$.

PINEDO, M. (2014): “¡No es un algo, pero tampoco una nada! Mente y normatividad”, Análisis. Revista de investigación filosófica, $\mathrm{n}^{\circ}$ 1, (2014), pp. 121-160. https://papiro.unizar.es/ojs/index.php/analisis/article/view/980.

SANTAYANA, G. (1913): Winds of Doctrine. Studies in Contemporary Opinion, Nueva York: Scribner's.

Santayana, G. (1914): "The Coming Philosophy", The Journal of Philosophy, Psychology and Scientific Methods 11.17 (1914), pp. 449-463. http://www.jstor.org/stable/2013439.

SANTAYANA, G. (1942): Realms of Being, Nueva York: Scribner's. Edición conjunta de The Realm of Essence, The Realm of Matter, The Realm of Truth y The Realm of Spirit.

SANTAYANA, G. (1954): The Life of Reason or The Phases of Human Progress. Revised by the Author in Collaboration with Daniel Cory, Nueva York: Scribner's. Primera edición de 1906.

SAntAyAnA, G. (2001): The Letters of George Santayana. Book One (1868-1909), W. G. Holzberger, ed., Cambridge (Massachusetts) y Londres: The MIT Press.

Santayana, G. (2002): Personas y lugares, traducción de Pedro García, Madrid: Trotta. Primera edición de 1944.

SANTAYANA, G. (2005): "Revolución en la ciencia", traducción de Daniel Moreno, Limbo (Teorema XXIV/3) no 22, (2005), pp. 1-8. La edición original es de 1928. http:/ / dialnet.unirioja.es/servlet/articulo?codigo $=2976140$. 
SANTAYANA, G. (2006a): “Algunos significados de la palabra 'es", traducción de Daniel Moreno, Revista de Occidente, 298, (2006), pp. 5-26. Primera edición de 1924.

SantayanA, G. (2006b): Platonismo y vida espiritual, traducción de Daniel Moreno, Madrid: Trotta. Edición original de 1927.

Santayana, G. (2011): Escepticismo y fe animal, traducción de Ángel M. Faerna, Madrid: Antonio Machado Libros.

Santayana at 150. International Interpretations, editado por Mattew C. Flamm, Giuseppe Patella y Jennifer A. Rea, Lexington Books, 2014. [Actas del IV Congreso Internacional sobre Santayana].

Santayana: un pensador universal, José Beltrán, Manuel Garrido y Sergio Sevilla, eds., Universidad de Valencia, Valencia, 2011. [Actas del III Congreso Internacional sobre Santayana].

SAVATER, F. (2012): Acerca de Santayana, Valencia: PUV.

Under Any Sky: Contemporary Readings of George Santayana, Matt Flamm yChris Skowroñski, eds, Cambridge Scholars Publishing, Newcastle, 2007. [Actas del II Congreso Internacional sobre Santayana].

VALDÉS, L. (2015): “Manuel Garrido Jiménez (1925-2015)”, Teorema, vol. XXXIV/1, (2015), pp. 199-207,

http://www.unioviedo.es/Teorema/docs/Obituario_teorema_Garrido.pdf 